\title{
Por que razão pretendeis ser pagos às nossas expensas? Pobreza e desigualdade no Segundo discurso de Rousseau
}

\author{
What right have you to demand payment of us? Poverty and inequality \\ in Rousseau's Second discourse
}

Hélio Alexandre da Silva

helio.alexandre@unesp.br

(Universidade Estadual Paulista, campus Franca, São Paulo, Brasil)

\begin{abstract}
Resumo: 0 objetivo deste trabalho é trazer a pobreza para o centro do debate que Rousseau empreende particularmente no Segundo discurso. Ainda que a questão central tratada ali seja a origem da desigualdade, é notável o papel que a pobreza possui como um de seus polos constitutivos. Assim, o caminho será percorrido em três passos, de modo que o primeiro trata de reconstruir o trajeto de Rousseau, destacando os aspectos que dão forma ao núcleo do argumento sobre a origem da desigualdade; o segundo apresenta o binômio prejuízo-privilégio como elemento central para entender os contornos da desigualdade, tomada a partir da divisão entre ricos e pobres; por fim, o terceiro passo pretende apontar as dificuldades presentes no modo com que Neuhouser interpreta a pobreza e a origem da dominação no Segundo discurso.
\end{abstract}

Palavras-chave: desigualdade; dominação; pobreza; Neuhouser.

\begin{abstract}
The purpose of this work is to bring poverty to the center of the debate that Rousseau particularly engages in the Second Discourse. Although the central issue there is the origin of the inequality, it is remarkable the role that poverty has as one of its constituent sides. Thus, the path will be covered in three steps so that the first deals to rebuild Rousseau way highlighting the aspects that form the core of the argument on the origin of inequality; the second one presents the prejudice-privilege binomial as a central element to understand the contours of inequality taken from the division between rich and poor, and finally, the third step aims to point out the difficulties present in the way in which Neuhouser interprets poverty and origin of domination in the Second Discourse.
\end{abstract}

Keywords: inequality; domination; poverty; Neuhouser.

DOI: http://dx.doi.org/10.11606/issn.2318-9800.v24i1p115-132

\section{Introdução}

Uma das formas de se aproximar da filosofia é reconhecer que ela reúne um determinado conjunto de problemas específicos, selecionados pelo crivo crítico da história, como objeto de dedicação dos filósofos. Uma vez decantados com o transcorrer dos séculos, esses problemas são extraídos de temas como a justiça, a liberdade, o homem, o conhecimento, o belo, a morte, a ética, a moral, a felicidade, 
a política entre tantos outros, tomando contornos diversos e compondo, ao longo do tempo, um cardápio heterogêneo. Lenta e progressivamente esses temas e problemas se sedimentaram de modo a estabelecer uma espécie de locus comum filosófico e, assim, o campo de interesses clássicos da filosofia. É desse lugar que sistematicamente têm surgido os desafios que se transformam nos principiais responsáveis por tirar o que Rousseau chama de "sono tranquilo do filósofo" (Rousseau, 1983a, p. 254).

Entretanto, nesse amplo campo composto de problemas capazes de arrancar o filósofo do seu leito, muito raramente encontra-se um tratamento exaustivo a um dos fenômenos mais antigos que preenche o convívio social. Se pode ser tomada como exagerada a afirmação de que a pobreza foi sistematicamente ignorada pelos grandes sistemas filosóficos, certamente não o é afirmar que ela jamais atingiu, na tradição filosófica, o status e o tratamento à altura daquele dispensado aos temas clássicos. Contudo, tratar dos motivos que eventualmente conduziram o pensamento filosófico nessa direção não é uma questão que pode receber o cuidado necessário nesse espaço. Bem menos ambiciosa, a pretensão aqui é tentar encontrar, dando ênfase particular ao Segundo discurso de Jean-Jacques Rousseau, os contornos que fazem dele um dos precursores de um debate filosófico sobre a pobreza que, de resto, ainda não foi propriamente construído.

\section{Origem da desigualdade}

Enquanto fenômeno decisivo para melhor compreender a organização política e social, a pobreza aparece em alguns momentos do texto de Rousseau como elemento de análise privilegiado, capaz de iluminar aspectos invisíveis à primeira vista. Mais do que isso, tentar compreender os traços mais precisos da pobreza é uma forma de qualificar a investigação de problemas como a desigualdade, a origem da riqueza, os aspectos mais relevantes das paixões humanas e as formas das instituições políticas. Ainda que sua preocupação central seja investigar as origens da desigualdade, o autor do Emílio trilha um caminho que oferece pistas importantes sobre os contornos e o lugar que a pobreza ocupa nesse contexto. Mesmo que seja possível encontrar, precisamente na primeira parte do Segundo discurso, uma incursão cuidadosa sobre os principais traços de um hipotético estado de natureza, não resta qualquer dúvida de que a pobreza e a desigualdade são produtos da forma com que o estado social se constituiu. Por isso, a construção das linhas fundamentais de uma filosofia social ${ }^{1}$

\footnotetext{
1 No texto "Patologias do social: tradição e atualidade da filosofia social", Axel Honneth recupera a filosofia moderna para destacar o peso do pensamento de Rousseau para o surgimento da filosofia social. Segundo o autor alemão, Rousseau teria sido o primeiro a tematizar os problemas sociais gerados pela legitimação moderna do poder político e, nesse sentido, o primeiro a fazer filosofia social. Honneth explica o objeto da filosofia social como a necessidade de "definir e analisar o processo de evolução da sociedade que aparece enquanto evoluções parciais ou distúrbios, isto é, enquanto 'patologias do social'” (Honneth, 2008, p. 40). Mais precisamente sobre os contornos
} 
capaz de explicar tanto as causas da desigualdade quanto as formas de lidar com ela é um dos resultados produzidos pelo esforço teórico de Rousseau.

Já no prefácio ele apresenta ao seu leitor a natureza do desafio diante do qual se vê imerso, a saber, "alcançar noções exatas" sobre um "estado que não mais existe, que talvez nunca tenha existido, que provavelmente jamais existirá". A busca por essa exatidão não é apenas uma amostra da pretensão teórica almejada pelo autor, mas uma necessidade normativa derivada de um dos problemas posto pelo texto, a saber, "bem julgar nosso estado presente” (Rousseau, 1983a, p. 2289) e responder à questão sobre a origem da desigualdade. Sendo esse o horizonte vislumbrado, Rousseau parte de uma análise do seu tempo para retornar a um estado natural e, com isso, encontrar critérios para, em seguida, ser capaz de avaliar criticamente a desigualdade. Assim, constrói, de um lado, um movimento com pretensões descritivas ${ }^{2}$ que procura as origens da desigualdade; de outro, um movimento com pretensões normativas que questiona sua legitimidade (Neuhouser, 2014, p. 4). Como consequência, inicialmente vê-se que, impelido apenas pela natureza e por seu "impulso interior", mulheres e homens "jamais far[ão] qualquer mal” uns aos outros salvo nos casos em que a própria conservação estiver em risco. Porém, em seguida, "considerando a sociedade humana”, o que se vê é que a relação entre os fortes e os fracos, os ricos e os pobres resulta invariavelmente na "violência dos homens poderosos e [n]a opressão dos fracos” (Rousseau, 1983a, p. 231).

O convívio cotidiano faz com que se estendam as ligações e os laços entre as pessoas. O resultado disso é que a disputa pela estima pública passa a ter um preço e, desse modo, a consideração acerca da beleza, da habilidade, da força física e da malícia espiritual, tudo tomado de uma só vez, configura o "primeiro passo tanto para a desigualdade 3 quanto para o vício” (Rousseau, 1983a, p. 263). A desigualdade nasce, portanto, da busca crescente e sistemática por maior reconhecimento público que, por sua vez, é capaz de transformar-se de sentimento socialmente forjado

da filosofia social, Franck Fischbach ressalta que seu aspecto central reside em seu caráter preponderantemente normativo. Entretanto, "não é verdade que a filosofia social captaria o sentido normativo do social lá onde a sociologia deveria se contentar com uma descrição do social capaz apenas de compreendê-lo como uma ordem existente de fato; não é uma questão de presença ou de ausência do normativo, mas uma questão de preponderância. A filosofia, em sua concepção do social, o considera preponderantemente pelo viés de sua normatividade" (Fischbach, 2017, p. 183184. grifo meu).

2 Naturalmente, aqui não se trata de aproximar o esforço teórico de Rousseau àquele desenvolvido por Marx quando trata da acumulação primitiva. Enquanto Marx descreve, de fato, acontecimentos históricos e o faz servindo-se de provas documentais, Rousseau propõe uma situação hipotética, não histórica, para a qual não há como oferecer provas.

3 Trata-se aqui sempre da desigualdade social. Rousseau faz uma distinção entre esta e a desigualdade natural, que é marcada pelas distinções de forças corpóreas e espirituais, idade, saúde, etc. Esse tipo de desigualdade "natural está longe de ter (...) tanta realidade e influência quanto pretendem" os que a ela se dedicam (Rousseau, 1983a, p.257). Assim, ainda que naturais, tais desigualdades não criam assimetrias de direitos, de tal modo que não se constituem em problema normativo a ser submetido à crítica. 0 que realmente importa, portanto, são as origens das desigualdades sociais. 
em uma "verdadeira necessidade" que, assim como o ciúme, pode eventualmente conduzir a "sacrifícios de sangue humano". Todos buscam vingar, na proporção da sua auto-consideração, o desprezo a que são eventualmente submetidos e tornam-se assim, no mais das vezes, "sanguinários e cruéis" (Rousseau, 1983a, p. 263). Desse modo, as "luzes funestas do homem civil" (Rousseau, 1983a, p. 264) vão pouco a pouco afogando a piedade natural e, guiadas pelo "amor ao bem estar" e pela busca por "comodidades" (Rousseau, 1983a, p. 261-262), impulsionam o mergulho nas tensões da vida social.

Como é próprio do pensamento rousseauniano (cf. Silva, 2014, p. 35-62), há aqui uma tensão que envolve o objeto a ser investigado e as condições de possibilidade que influenciam a forma da investigação. A dificuldade está precisamente no fato de que para estudar o homem natural é preciso possuir "luzes que só se desenvolvem com muito trabalho (...) no próprio seio da sociedade” (Rousseau, 1983a, p. 230). 0 aprimoramento social da razão, um dos responsáveis pelo distanciamento progressivo da natureza, é condição necessária para a produção das pretensas "noções exatas" que permitem o conhecimento da natureza e, consequentemente, da origem da desigualdade. Se a dificuldade implicada no procedimento é reconhecida pelo autor, isso não significa que ele tenha uma alternativa mais eficaz para dar cabo do problema posto. 0 "estudo do homem original, de suas verdadeiras necessidades e dos princípios fundamentais de seus deveres" é o único caminho confiável capaz de "afastar a multidão de dificuldades" que se apresenta quando o objetivo é investigar "a origem da desigualdade" (Rousseau, 1983a, p. 231).

Esse objetivo exposto por Rousseau é visto por Neuhouser (2014, p. 5) como um empreendimento genealógico 4 que, ao procurar a origem da desigualdade tornase também capaz de acessar seu valor. Tal esforço permite, ao mesmo tempo, a avaliação do estado social presente e a construção de um horizonte normativo capaz de mostrar não apenas o caráter ilegítimo da desigualdade mas - e esse aspecto me interessa mais - a sistemática dominação dos ricos sobre os pobres, dominação esta, ressalta Rousseau, que surge graças à “dependência mútua dos homens" e às “necessidades recíprocas que os unem” (Rousseau, 1983a, p. 258).

Essa genealogia, conforme nomeia Neuhouser, tem o mérito de mostrar que a passagem do estado natural para as primeiras formas de sociabilidade trouxe o aumento das técnicas de cultivo e a ampliação das possibilidades de oferecer novas comodidades. Nesse momento vale destacar que não é outra coisa senão o "amor ao bem estar" aquilo que se impõe como "único móvel das ações humanas" (Rousseau, $1983 a$, p. 261). No entanto, tal passagem, guiada em grande medida por essa espécie particular de amor, introduziu a desigualdade, a propriedade e a necessidade do trabalho. 0 produto do progresso trouxe comodidades, civilizou mulheres e homens

4 Sobre os contornos mais precisos da genealogia rousseauniana, cf: Neuhouser, 2014, p. 105-106. 
mas também arruinou a humanidade ao permitir que seu suor regasse, a um só tempo, as colheitas, a escravidão e a miséria (Rousseau, 1983a, p. 265). A natureza pretendeu formar mulheres e homens, mas a sociedade os tornou crianças dependentes do auxílio dos outros para satisfazer as próprias necessidades. Enquanto os pobres precisam dos ricos para não serem sugados pela miséria, estes precisam dos pobres para alimentar seu “orgulho" e sua "vaidade pueril” (Rousseau, 1995, p. 68). Assim, embora a socialização implique em mútua dependência e reciprocidade, isso não significa, absolutamente, que a partilha da riqueza e das comodidades trazidas por ela ocorra de forma horizontal.

\section{Desigualdade e pobreza entre natureza e sociedade}

Antes, porém, de analisar os traços mais precisos da pobreza e sua relação com a desigualdade, vale destacar que Rousseau concebe uma espécie de estágio social intermediário entre o estado de simples natureza e o estado social já desenvolvido. Esse é um momento decisivo para o tema que nos ocupa precisamente porque traz elementos de sociabilidade sem, no entanto, apresentar a cristalização social da pobreza como um fato politicamente autorizado.

Entre o estado de natureza e o estado social marcado pela divisão entre ricos e pobres, há um momento em que mulheres e homens são capazes de viver guiados particularmente pela "afeição recíproca" e pela "liberdade". Esses dois aspectos são decisivos para construir o quadro desenhado por Rousseau nesse estágio marcado por uma "primeira revolução [que] determinou o estabelecimento e a distinção das famílias e que introduziu uma espécie de propriedade" (Rousseau, 1983a, p. 262). Entretanto, o surgimento da propriedade aqui ainda não é determinante para produzir "brigas e combates", embora elas eventualmente possam ocorrer. Essa é a época em que a reunião um pouco menos esporádica de homens e mulheres, que não vivem mais completamente isolados, formam famílias que passam a operar como "uma pequena sociedade", muito embora esse "novo estado" ainda seja marcado por uma vida primordialmente "simples e solitária”. É o momento em que há formas de propriedade mas que, nem por isso, elas necessariamente se tornam objeto de cobiça, tampouco causa suficiente para que ninguém alimente o ímpeto de "apropriar-se da [propriedade] de seu vizinho", de modo que a vida transcorre "com necessidades muito limitadas" (Rousseau, 1983a, p. 262). ${ }^{5}$ Esse período é marcado

\footnotetext{
5 Esse momento, a que o próprio Rousseau chama de "juventude do mundo" (Rousseau, 1983, p. 264), alguns autores chamam de "era das cabanas" (Nicodème, 2010, p. 138) ou simplesmente de "segundo estado de natureza"; ele sintetiza o primeiro movimento realmente relevante de distanciamento da natureza, porém ainda não apresenta todos os vícios que vão se sedimentar com o estabelecimento da vida social. Esse é também um dos períodos que Honneth não ilumina suficientemente quando constrói sua interpretação de Rousseau e, por isso, acaba por introduzir dificuldades na leitura que produz acerca do texto do autor do Contrato social. Sobre tais dificuldades, ver Nicodème, 2010.
} 
por ser aquele capaz de caracterizar de forma mais precisa uma "posição média exata entre a indolência do estado primitivo e a atividade petulante do nosso amor próprio". Contra os que insistem em atribuir a Rousseau o papel de divulgador de uma espécie de vida boa, possível apenas no contexto pré-social e imediatamente corrompida tão logo se sociabilizara, ele deixa claro que esse estágio intermediário, experienciado pelas mulheres e homens, é que "deve ter sido a época mais feliz" (Rousseau, 1983a, p. 264).

Aqui, no entanto, reside o momento preciso em que, guiados pela busca de “inúmeras espécies de comodidades desconhecidas de seus antepassados", mulheres e homens impõem a si mesmos "a primeira fonte de males que prepararam para seus descendentes". A aquisição de novas comodidades trouxe consigo o enfraquecimento do corpo e do espírito que, a um só tempo, as transformaram em "verdadeiras necessidades". A busca pelo bem estar ajudou a construir o ambiente fértil para que as facilidades, recentemente criadas, se constituíssem pouco a pouco em matéria indispensável para a vida. Com isso, "a privação se tornou muito mais cruel do que doce fora sua posse, e os homens sentiam-se infelizes por perdê-las, sem terem sido felizes por possuí-las" (Rousseau, 1983a, p. 262). Nesse momento vale destacar dois aspectos: o primeiro é o surgimento da pobreza como um estado que nasce do progressivo movimento de distanciamento da natureza; o segundo é o papel das necessidades que surgem com a vida social.

Quanto ao primeiro aspecto, deve-se notar como Rousseau constrói seu argumento no sentido de mostrar que a pobreza não é o resultado da perda de algo, mas de uma forma bastante particular de progresso ${ }^{6}$ social. No estado natural não se fazia necessário, para bem viver, o trabalho contínuo ou o acúmulo de objetos e ferramentas específicos, na medida em que a natureza era pródiga em oferecer os meios para uma vida tranquila e sem grandes conflitos. Numa palavra, não havia nem era necessário que houvesse propriedade. Porém, o desenvolvimento da agricultura e da metalurgia permitiu que aqueles que empregavam sistematicamente seus esforços na lavoura se tornassem proprietários daquilo que tiravam da terra com seu trabalho. 0 progresso dessas novidades conduziu à necessidade de que os proprietários contassem com a ajuda dos não-proprietários. Para acumular riqueza, os primeiros precisaram submeter os segundos, por entenderem que "a única forma

\footnotetext{
6 Nesse sentido, Maria das Graças Souza aponta que, em Rousseau, o avanço da história é, na verdade, um retrocesso, isto é, "o percurso da história dos homens não pode ser entendido como progresso, se progresso for avanço em direção ao melhor”. Paradoxalmente, “'o progresso das coisas' traz o declínio dos homens e das instituições". Portanto a noção de declínio ou degeneração em Rousseau "integra a noção de progresso" e, desse modo, o autor se coloca na "contracorrente de sua época", uma vez que, ainda de acordo com a autora, "o século XVIII é exatamente conhecido como o século das Luzes e do progresso". Ao mostrar que o progresso é uma forma de desnaturação e, portanto, de corrupção dos sentimentos naturais que tornavam o homem forte e independente, Rousseau segue um caminho diferente daquele defendido pelo lluminismo de sua época (cf. Souza, 2011, p. 73 ss).
} 
de prosperar [seria] às expensas dos outros”. Finalmente, os não-proprietários, "tendo se tornado pobres sem nada ter perdido (...) viram-se obrigados a receber ou roubar sua subsistência da mão dos ricos"; floresceu daí "a dominação e a servidão (...) a violência e os roubos" (Rousseau, 1983a, p. 267-8). Vale notar como Rousseau situa o surgimento das riquezas como acúmulo daquilo que se produziu através de um trabalho contínuo que, até então, era inteiramente desnecessário. E mais que isso, uma vez rompida a igualdade seguiu-se a desordem e a "sociedade nascente foi colocada no mais tremendo estado de guerra" (Rousseau, 1983a, p. 268).

Quanto a isso, alguém poderia objetar se não estaria de acordo com a lei natural atribuir àquele que primeiro ocupou a terra e nela trabalhou um direito de mando sobre os demais. A esse respeito, Rousseau é taxativo: "por que razão pretendeis ser pagos às nossas expensas por um trabalho que não vos impusemos" e que faz com que "uma multidão de vossos irmãos" sofra e pereça pela falta daquilo que te sobra? (Rousseau, 1983a, p. 268, trad. modificada). Rousseau se resguarda no fato que não é razoável, para alguém no estado de natureza, supor que exista qualquer necessidade natural que obrigue mulheres e homens a se submeterem a um trabalho sistemático. Se a natureza oferece o que é necessário, então não há motivo para abandonar o estado natural, marcado entre outros aspectos, por certa preguiça. Sobre esse particular vale destacar que o homem natural vive "Só e desocupado (...) deve gostar de dormir e ter o sono leve, como os animais que, pensando pouco, dormem, por assim dizer, todo o tempo em que não estão pensando" (Rousseau, 1983a, p. 242, grifo meu). Se alguém resolveu abandonar essa condição para impor a si mesmo o peso árduo do trabalho, guiado pelo amor ao bem estar e pela busca de comodidades ainda inexistentes, isso não significa, absolutamente, que ele está autorizado a impor esse mesmo peso aos demais. 0 fato de ter sido o primeiro a ocupar a terra e nela trabalhar sistematicamente não atribui ao ocupante nenhum direito sobre os que permaneceram entregues aos auspícios da natureza.

O segundo aspecto é o papel desempenhado pelo surgimento de novas necessidades que, quando limitadas e guiadas pela busca da liberdade e da afeição recíproca, operam como um obstáculo que impede que o surgimento da propriedade seja causa determinante da emergência de conflitos sociais. Os conflitos e os "males sociais" surgem quando as comodidades, até então completamente desconhecidas, passam a operar como algo indispensável ou, para ser preciso, como "verdadeiras necessidades". A partir desse momento, já não é mais possível viver sem elas sem que, ao mesmo tempo, se tenha a sensação de ser privado do essencial. A fruição sistemática de uma comodidade não apenas alimenta o "amor ao bem estar" como torna necessário o acesso a algo que há pouco sequer existia. Com isso, nota-se que a comodidade socialmente construída se transforma de tal modo em necessidade que sua privação aparece não apenas como um nítido símbolo de crueldade, mas também 
como fonte incontornável de infelicidade. Voltarei a esse aspecto mais adiante.

Quanto mais se acelera o progresso social na direção apontada por Rousseau, mais se aprofundam os elementos que marcam a desigualdade. Nesse sentido, o "estabelecimento da lei e do direto de propriedade", seguido da "instituição da magistratura" e da "transformação do poder legítimo em poder arbitrário" (Rousseau, 1983a, p. 277), foram os três maiores acontecimentos políticos-jurídicos que cristalizaram a desigualdade como traço fundamental das assim chamadas sociedades modernas. Esses acontecimentos, por sua vez, sancionaram três consequências sociais igualmente marcantes, a saber, a autorização da divisão entre "rico e pobre", "poderoso e fraco" e, finalmente, "senhor e escravo", que não é outra coisa senão “o último grau da desigualdade” (Rousseau, 1983a, p. 277).

\section{Pobreza e riqueza: prejuízo e privilégio}

O estágio intermediário de que fala Rousseau, ao ser deixado pra trás, abre caminho para o aprofundamento da desigualdade e, consequentemente, da divisão entre ricos e pobres. Diferente da natural, a desigualdade social é aquela "estabelecida ou (...) autorizada pelo consentimento dos homens" e consiste, precisamente, "nos vários privilégios que gozam alguns em prejuízo de outros". E quais são esses privilégios? São aqueles direitos garantidos com exclusividade por uma parte específica da sociedade e que se caracterizam pela capacidade de impor, em alguma medida, a obediência. Ou ainda, são as marcas que atribuem aos seus possuidores o direito de serem homenageados ou, para ficar com a letra do texto, são simplesmente aqueles atributos conferidos aos "mais ricos" e "mais poderosos" (Rousseau, 1983a, p. 235, grifos meus).

Vale notar aqui que a assimetria marcada pela desigualdade entre ricos e pobres pode ser melhor apresentada quando se atribui centralidade às duas dimensões distintas que particularizam cada um de seus polos, a saber, o privilégio no caso da riqueza e o prejuízo no caso da pobreza. Uma sociedade marcada pela desigualdade entre ricos e pobres é também uma forma de organização orientada pelo binômio privilégio-prejuízo. Essa parece ser uma maneira promissora de destacar a dimensão central que confere amplitude teórico normativa à desigualdade tal como formulada nos termos de Rousseau. Toda forma de desigualdade social implica uma relação de privilégio-prejuízo. 0 reconhecimento público que frequentemente se atribui a uns (ricos e poderosos), sistematicamente se nega a outros (pobres e fracos). A dominação, como não poderia ser diferente, é uma das consequências produzidas por relações sociais dessa natureza. As formas de reconhecimento social possíveis não podem ser partilhadas quando o que organiza as formas de vida são relações pautadas pela dinâmica privilégio-prejuízo. Nesse sentido, receber homenagens - 
que são símbolos de estima pública -, e possuir o direito de fazer-se obedecer - que é um trunfo político - são privilégios que os ricos exercem contra os pobres. Se, como destacado acima, o procedimento adotado por Rousseau pode ser visto como genealógico, então é importante entender qual a origem desses privilégios que, ao serem socialmente aplicados, causam prejuízo aos pobres.

De início é preciso deixar claro que essa origem não reside na força ou na virtude. Nesse particular, não há qualquer ligação entre as desigualdades naturais e as sociais. Não é difícil notar que nas sociedades modernas, tal como descritas por Rousseau, ser fisicamente mais forte ou de espírito mais vivo não implica necessariamente ser mais rico, assim como ser fisicamente mais fraco e de espírito pusilânime não torna ninguém mais pobre. Levantar a questão de se o rico goza de privilégios porque é mais forte, sábio e virtuoso "seria uma boa questão para discutir entre escravos ouvidos por seus senhores" (Rousseau, 1983a, p. 235). Pessoas "razoáveis e livres" jamais procuram nas diferenças de espírito ou nas capacidades físicas a origem fundamental do privilégio dos ricos ou do prejuízo dos pobres. As diferenças naturais não se constituem em fontes legítimas capazes de produzir hierarquias de direito, tampouco legitimam desigualdades sociais como as que existem entre ricos e pobres.

A afirmação e o aprofundamento de um ordenamento social marcado pelo prejuízo dos pobres e pelo privilégio dos ricos conectam-se, isto sim, com o distanciamento da natureza e a substituição do direito pela violência. Tratase, portanto, de entender qual foi o “encadeamento de prodígios" que permitiu o florescimento desse tipo de dominação (Rousseau, 1983a, p. 235). Isso porque, mesmo que entre ricos e pobres exista uma dependência mútua, ela é ancorada em uma desigualdade fundamental. Enquanto o rico necessita dos serviços do pobre, este necessita do socorro do rico (Rousseau, 1983a, p. 267); ou ainda, enquanto o pobre morre por não ter satisfeitas as suas necessidades, o rico morre por seus excessos (Rousseau, 1983a, p. 292). O rico depende do pobre para acumular sua riqueza ao passo que o pobre necessita do rico para não chegar ao limite último da miséria.

Os esforços na direção de elencar semelhanças entre ricos ${ }^{7}$ e pobres terminam por produzir um efeito de neutralização do verdadeiro abismo existente entre eles. Quando se destaca, por exemplo, momentos de sofrimento e de dor que podem ser experienciados por uns e por outros, pode-se ter uma impressão de proximidade.

\footnotetext{
7 Sobre a riqueza e o rico, Claire Pignol destaca uma diferença entre falso e verdadeiro rico. 0 elemento que distingue o primeiro do segundo é a piedade. 0 verdadeiro rico possuiria maior capacidade de sentir os males do pobre na medida em que cultiva esse traço natural que aproxima a espécie por meio do sentimento de partilha da dor e do sofrimento (cf. Pignol, 2010/2). Pareceme, contudo, que esse elemento moral em nada modifica o aspecto central e definitivo de que o rico carrega privilégios que são mobilizados invariavelmente contra os pobres. Mesmo que sinceramente guiado pela piedade, o verdadeiro rico não terá neutralizado seus privilégios, ainda que tenha aquiescido sua consciência ou aliviado sua culpa.
} 
Contudo, se a espécie os aproxima, a sociedade os distancia. Nesse sentido, quando o rico reivindica o princípio da igualdade natural como forma de legitimação do seu lugar de privilégio, o que ocorre, na realidade, é um expediente cínico de falsa aproximação entre atores socialmente desiguais. Se o desenvolvimento social ampliou e diversificou os desejos, que naturalmente se reduziam praticamente a saciar a fome e o apetite sexual, ele se deu de tal modo que impediu a igualdade de acesso às riquezas necessárias para satisfazê-los. Assim, tentativas de produzir algum tipo de simetria entre ricos e pobres não passam de "sofisma grosseiro!". Isso porque, por um lado, "as penas do rico não vêm de sua situação social e sim dele mesmo, que delas abusa"; por outro, não há hábito que possa arrancar o sofrimento daqueles pobres que padecem com "o sentimento físico da fadiga, do esgotamento, da fome". Para estes, nem "o bom estado de espírito nem a sabedoria lhe[s] servem para isentá-lo[s] dos males de sua condição" (Rousseau, 1995, p. 252-3). Note-se que $o$ alvo aqui não é a falta que caracteriza a pobreza propriamente dita, mas as atitudes tomadas sistematicamente pelo rico que utiliza sua condição para se impor diante dos pobres. Trata-se, portanto, da dimensão política trazida pelo problema da desigualdade entre ricos e pobres. Nesse particular vale lembrar que Rousseau afirma que o rico provavelmente deixaria de ser feliz se o povo deixasse a miséria (Rousseau, 1983a, p. 279), o que nos autoriza a pensar que, sob a ótica do rico, a diminuição da dominação pode causar a diminuição de sua própria felicidade.

A convivência social faz convergir todos os esforços individuais na direção de dois grandes objetivos: o primeiro é "alcançar para si as comodidades da vida"; o segundo é buscar tanto quanto possível a "consideração dos demais" (Rousseau, 1983a, p. 307, grifo meu). Evidentemente, no mais das vezes, a aquisição do segundo depende do primeiro. Os que precisam trabalhar para os ricos, para sobreviver, lidam com o "esgotamento físico" e com a "fadiga" e, dificilmente, serão dignos de atrair a "consideração dos demais". A esse respeito pergunte-se, por exemplo, que tipo de virtude atrairá o olhar para aquele cuja vida é marcada, antes de tudo, pela submissão e pelo esforço em aliviar seus próprios sofrimentos? Que tipo de estima pública merecerá aquele que, para sobreviver, se debate contra o cansaço físico ou a fome? Por certo, não há atrativos, particularmente para os ricos, em vidas marcadas pela obediência e pela experiência sistêmica da falta de comodidades. Nesse sentido, se a sociedade produz nos homens e nas mulheres novos desejos que geram a expectativa de obter comodidades e reconhecimento público, a desigualdade, por sua vez, produz sistematicamente obstáculos que impedem os pobres de realizá-los.

A incapacidade de satisfazer os desejos é um dos elementos definidores da pobreza e isso confere um lugar decisivo para a necessidade. Parte importante da crítica que Rousseau dirige aos ricos está voltada para o uso que eles fazem da sua riqueza. Pouco a pouco eles se vêem abraçados às "delícias vãs" que thes roubam o 
“gosto da verdadeira felicidade (...) e das virtudes sólidas" (Rousseau, 1983a, p. 221), promovendo luxos dispendiosos que alimentam a vaidade através da ostentação, mas que não são, em si mesmos, necessários.

Tanto no Segundo discurso quanto no Emílio, Rousseau entende que as necessidades reúnem tanto aspectos naturais quanto sociais. Se se desconsiderarem as necessidades físicas, destaca Rousseau, “todas as nossas outras necessidades são devidas ao hábito, antes do qual não eram necessidades, ou aos nossos desejos, e não se deseja aquilo que não se está em condições de conhecer" (Rousseau, 1983a, p. 302. grifo meu). As necessidades estão diretamente ligadas à capacidade de aproximar desejos e recursos, ou seja, é necessário tudo aquilo que pode ser alcançado sem desfazer o equilíbrio entre faculdades e desejos. 0 distanciamento da natureza provocado pela vida social tornou possível o aprofundamento da assimetria entre eles, desfazendo assim a "perfeita igualdade [entre] o poder e a vontade" e criando necessidades tais que as faculdades e os recursos disponíveis são incapazes de suprir completamente. Rousseau chega mesmo a afirmar que "o homem é muito forte quando se contenta em ser o que é” (Rousseau, 1995, p. 63). Isso poderia levar à falsa compreensão de que certa aceitação resignada da própria condição seria o caminho mais razoável a tomar frente aos males que a desigualdade social produz ao aprofundar a assimetria entre desejos e faculdades. Entretanto, o remédio para a impossibilidade de acessar aquilo que é necessário para satisfazer nossos desejos não reside, definitivamente, na defesa de uma espécie de universalização do que poderia se chamar aqui de um deliberado voto de pobreza. Se a origem de "nossa miséria" situa-se na "desproporção entre nossos desejos e nossas faculdades", isso não significa que a superação desse estado se dê por meio de uma recusa deliberada do acesso àquilo que satisfaz os desejos. Ao contrário, o "caminho da felicidade verdadeira" não implica "em diminuir nossos desejos". Isso seria como abdicar de parte das faculdades que, ficando "ociosas", impediria o gozo pleno de "todo nosso ser" (Rousseau, 1995, p. 62). Assim, aquilo que o desejo deseja é uma necessidade desde que não implique em promoção da desigualdade.

Entretanto, os desejos aumentam na medida em que a sociedade avança e as faculdades se aperfeiçoam, de modo que "não se fica dois momentos no mesmo estado". Se a natureza oferece imediatamente "os desejos necessários, a (...) conservação e as faculdades suficientes para os satisfazer" (Rousseau, 1995, p. 62), a vida social, por sua vez, se constitui como uma espiral que faz com que os novos desejos de comodidade e de bem estar sejam sistematicamente universalizados antes que se universalizem as condições de satisfazê-los. Como já destacado, não é outra coisa senão o "amor ao bem estar" aquilo que se impõe como "único móvel das ações humanas” (Rousseau, 1983a, p. 261). Com isso, a satisfação dos desejos socialmente produzidos, ao ser posta em circulação em uma sociedade marcada pela 
divisão entre ricos e pobres, torna-se imediatamente um privilégio dos ricos.

Lidar com essa questão exige entender com mais cuidado os contornos da pobreza e da riqueza enquanto dois polos da desigualdade. Isso permitirá entender de forma mais precisa o caminho trilhado por Rousseau para ligar desigualdade, pobreza, riqueza e dominação.

Essa é uma das tarefas enfrentadas por Neuhouser (2014, p. 203) em sua análise do Segundo discurso, ao afirmar que a desigualdade é um problema na medida em que se constitui no grande obstáculo para o exercício da liberdade e, ao mesmo tempo, produz dominação. Ao tratar mais precisamente da forma com que Rousseau aborda a pobreza, ele ressalta que pobres não seriam os que possuem uma fração menor das riquezas, mas os que estão submetidos à experiência de "privação absoluta". O argumento ganha maior clareza quando Neuhouser destaca as razões pelas quais Rousseau elege a desigualdade, e não a pobreza, como fonte definitiva da dominação. Segundo ele, a pobreza não pode ser fonte última de dominação porque sempre é possível haver sociedades pobres sem, contudo, serem desiguais. Assim, muito embora a privação absoluta (pobreza) seja ruim por outras razões, isso não a transforma no fundamento da dominação e da obediência (Neuhouser, 2014, p. 204). Uma sociedade pode, nesses termos, ser profundamente marcada pela pobreza sem, contudo, exibir as marcas da desigualdade. Assim, Neuhouser pretende mostrar que Rousseau teria pensado a pobreza como um conceito absoluto, ou seja, é pobre aquele que experiencia a "privação absoluta" e convive com a total falta de meios para sobreviver.

Quanto a essas observações, há dois pontos que merecem ser desenvolvidos com um pouco mais de cuidado porque tocam no cerne da questão que nos ocupa. 0 primeiro é a concepção de pobreza como privação absoluta; o segundo é a afirmação de que a desigualdade, não a pobreza, é a fonte principal da dominação. Duas questões se impõem nesse momento: a primeira é se os textos de Rousseau autorizariam conceber a experiência da pobreza precisamente como privação absoluta; a outra é saber se, a partir de Rousseau, é possível haver desigualdade sem pobreza.

\section{Neuhouser: pobreza como "privação absoluta" e desigualdade como origem da dominação}

Para lidar com essas questões é preciso, de início, entender os contornos com que Neuhouser aborda a pobreza a partir de sua análise do Segundo discurso e, em

80 problema que guia a leitura que Neuhouser faz em Rousseau's critique of inequality é investigar como a filosofia pode ajudar a compreender os motivos que fazem da desigualdade um fenômeno tão presente nas sociedades modernas e, ao mesmo tempo, descobrir quando e por que essas desigualdades tornam-se moralmente objetáveis e, portanto, alvos legítimos da crítica social (Neuhouser, 2014, p. 3). 
seguida, aproximá-la da forma com que Rousseau realiza a mesma tarefa. Quando o intérprete compreende a pobreza como "privação absoluta" para explicar esse fenômeno e diferenciá-lo da desigualdade, particularmente naquilo que concerne à origem da dominação, ele deixa de captar uma sutileza que, a meu ver, retira do texto um elemento decisivo para bem compreender tanto a pobreza quanto a desigualdade. 0 texto de Rousseau fornece passagens suficientes que permitem compreender que a pobreza é fracionada tanto quanto a riqueza, o que seria o mesmo que afirmar que há os pobres, os mais pobres e os menos pobres, da mesma forma que há os ricos, os mais ricos e os menos ricos. É primordial considerar um pouco mais de perto esse ponto.

Neuhouser afirma que ser pobre é um elemento que conduz à dominação, mas "ser pobre e ter menos do que os outros" aumenta ainda mais a dominação (Neuhouser, 2014, p. 203). Para ser direto, o problema aqui é que Neuhouser parece confundir pobreza e miséria. A dificuldade de interpretações dessa natureza está precisamente no fato de que Rousseau não faz uma distinção clara entre pobreza e pobreza absoluta, tampouco afirma que pobreza seja exclusivamente um estado de privação absoluta. No entanto, invariavelmente, quando o que está em jogo é a desigualdade social, a fratura pressuposta ou é explicitamente apresentada como divisão entre ricos e pobres ou se permite ser reduzida a tanto. Ainda que sejam frequentes as referências à condição de miserabilidade, que "significa uma privação dolorosa e sofrimento do corpo e da alma” (Rousseau, 1983a, p. 151, grifo meu), não há indícios que autorizem aproximar pobreza e miséria como termos simplesmente intercambiáveis na obra de Rousseau. Quando Neuhouser define pobreza como privação absoluta, é exatamente essa aproximação que ele põe em marcha.

0 texto de Rousseau indica que a norma que orienta a abordagem crítica da desigualdade é construída a partir da divisão entre ricos e pobres sem, contudo, jamais deixar margens para uma compreensão da pobreza enquanto escassez completa dos meios de vida. Entretanto, e aqui parece estar o núcleo do problema não visualizado por Neuhouser, Rousseau não ignora totalmente que existam frações de pobreza e de riqueza. Há os ricos e os mais ricos tanto quanto há os pobres e os mais pobres. Para Rousseau, pobre não é aquele que vive, como quer Neuhouser, em estado de "absoluta privação", mas aquele que se submete ao rico porque olha mais para os que estão atrás do que para os que estão à frente (Rousseau, 1983a, p. 278). Definitivamente, a condição de pobreza não pode ser reduzida à de miserabilidade, esta sim, própria àqueles que experienciam o estado de carência completa ou privação absoluta.

Quando se refere ao pacto dos ricos, o "projeto (...) mais excogitado que até então passou pelo espírito humano", é óbvio para o leitor que Rousseau trata de um esforço empreendido pelos ricos. Mesmo "destituídos de razões legítimas”, eles prometem com o pacto “defender os fracos da opressão" por meio de "regulamentos 
de justiça e de paz, aos quais todos sejam obrigados a conformar-se". 0 resultado, no entanto, é o oposto do prometido, isto é, as forças reunidas acabam por instituir "novos entraves ao fraco e novas forças ao rico" (Rousseau, 1983a, p. 269). Com isso, os ricos propõem um pacto que cristaliza um estado artificial e resguarda a riqueza já acumulada de uns e a pobreza de muitos. Note-se que submeter-se ao pacto dos ricos não implica estar imerso na miséria completa e absoluta; aquele que se submete o faz olhando pra trás e com medo de que sua vida piore. Ter acesso a um conjunto particular de bens que alimentam o amor ao bem estar e trazem comodidades que antes não existiam não significa necessariamente o abandono da pobreza. Portanto, estabelecer os contornos mais precisos da pobreza em Rousseau não implica em considerá-la como privação absoluta. Nesses termos, parece mais razoável, porque mais de acordo com o texto, entender que quando a questão é precisamente a origem da dominação, Rousseau não se preocupa em estabelecer uma distinção rígida entre pobreza e desigualdade, como quer Neuhouser. Embora não se trate do mesmo fenômeno social, é possível, nesse particular, verificar entre elas mais convergências do que divergências.

Essa consideração leva ainda a outro aspecto que merece destaque na afirmação de Neuhouser segundo a qual ser pobre é um elemento que conduz à dominação, mas ser pobre e ter menos do que os outros aumenta ainda mais a dominação (Neuhouser, 2014, p. 203). Aqui o pressuposto trazido pelo intérprete é de que pode haver tanto sociedades compostas exclusivamente por pobres quanto exclusivamente por ricos, o que significaria que ninguém teria menos que ninguém e, portanto, não haveria dominação por não haver desigualdade. Esse é um raciocínio útil para uma consideração da pobreza pensada a partir do que poderia ser chamado de um recorte nacional e particularista, isto é, que procura qualificar a pobreza a partir de uma abordagem voltada para uma sociedade específica. Entretanto, o que parece mais condizente com os esforços de Rousseau é pensar tanto a pobreza quanto a desigualdade a partir de análises de natureza normativa e com pretensão de universalidade. ${ }^{9}$ Nesse sentido, a pobreza não parece ser um fenômeno que possa ter sua explicação completamente esgotada somente pela investigação de suas origens, circunscritas às formas de organização de uma sociedade, país ou região particular. As comodidades que ajudam a alimentar o que Rousseau chama de "amor ao bem estar" são socialmente construídas, o que significa que dificilmente podem ser consideradas exclusivamente dentro dos limites precisos de uma única sociedade sem considerar o necessário intercâmbio com outras. Desse modo, a partir do espírito e da letra do texto de Rousseau, é possível afirmar que se há desigualdade há pobres. Se não houver dentro de uma hipotética sociedade, composta por cidadãos exclusivamente ricos ou

9 Lembrando, com Fischbach, que a filosofia social é marcada não exclusivamente, mas preponderantemente pelo aspecto normativo. 
exclusivamente pobres, muito provavelmente haverá se esta mesma sociedade for considerada em relação a outras. O que está em jogo aqui é uma tensão permanente que perpassa o pensamento de Rousseau e que possui, de um lado, assim como formulado no Contrato social ou no Emílio, uma análise mais “particularista” segundo a qual não existe uma única comunidade humana, mas somente povos singulares; de outro lado, em uma análise genealógica mais condizente com o Segundo Discurso, ele assume a existência de uma ampla sociedade dos seres humanos ou, dito de outro modo, procura destacar a repetição sistêmica do mesmo acontecimento em todos os povos do mundo no mesmo momento histórico.

No Contrato social, Rousseau dá mostras mais claras de que pobreza não significa necessariamente privação absoluta quando destaca que a desigualdade que deve ser combatida por um estado legítimo é aquela que obriga o pobre vender-se para o rico e permite que o rico possa comprar o pobre. O objetivo de um sistema de legislação é oferecer leis capazes de garantir que "nenhum cidadão seja suficientemente opulento para poder comprar um outro e não haja nenhum tão pobre que se veja constrangido a vender-se" (Rousseau, 1983b, p. 66). Isso leva a crer que um nível de pobreza que não obrigue tal comércio não se constitui em um problema social de primeira ordem. Para retomar a diferença em relação à definição de Neuhouser, parece que não há razões para aceitar que pobreza seja sinônimo de privação absoluta, tampouco que a principal fonte da dominação seja a desigualdade. 0 que se mostra mais condizente com os textos rousseaunianos é entender que ser pobre invariavelmente implica ter menos do que outros. Como aparece claro no pacto dos ricos, esforço decisivo que pretende legitimar a desigualdade, o contrato se dá entre ricos e pobres e não entre os mais ricos e os menos ricos, tampouco entre os mais pobres e os menos pobres. O elemento central aqui é que há no texto do Segundo discurso uma construção normativa que compreende as diversas frações da sociedade sob apenas duas classes, os pobres e os ricos. Entretanto, isso parece insuficiente para afirmar que Rousseau ignora a existência do que pode ser chamado de frações de classe. O que é realmente decisivo é que a desigualdade originalmente diz respeito à cisão entre ricos e pobres, entre proprietários e não proprietários. É a distância entre eles, particularmente aquela que permite que o rico compre o pobre e o pobre se venda ao rico, que configura a desigualdade que precisa ser politicamente superada.

Não é aos miseráveis que convivem com a privação absoluta que Rousseau se refere quando denuncia os malefícios sociais da desigualdade, produto da divisão artificial entre ricos e pobres. Como já dito, é possível enxergar em Rousseau, precisamente naquilo que concerne ao tratamento da desigualdade, a consideração de frações de classes tanto entre os ricos quanto entre os pobres. Assim como existe o luxo ${ }^{10}$ - abuso produzido pelos que são “ávidos de suas próprias comodidades e da

$10 \mathrm{Em}$ todos os Estados, o luxo "é o pior de todos os males que possam advir" porque em última 
consideração dos demais" (Rousseau, 1983a, p. 294) - que corrompe os ricos e, em alguma medida, os diferencia entre os ricos e os mais ricos, ${ }^{11}$ há também entre os pobres uma diferença marcada pelo fato de que eles sempre olham "mais abaixo do que acima de si mesmos", de tal modo que sempre há entre eles os que são mais pobres (Rousseau, 1983a, p. 278).

Ao se compararem uns aos outros, alguns ricos reclamam do luxo que querem e ainda não possuem; os pobres, por sua vez, sempre encontram alguma satisfação quando olham para trás e vêem que os grilhões podem estar ainda mais pesados nos ombros dos outros. Assim, por um lado, a comparação entre os ricos e os mais ricos se dá sempre em busca do maior acúmulo e maior acesso à riqueza e, por outro, a comparação entre os pobres se dá sempre em busca do menor sofrimento. Como só é possível desejar o que se pode conhecer, os pobres, só com muita dificuldade, desejam o conforto do rico. Para eles é mais fácil, ao olharem para trás, conceber e reunir esforços para se afastar dos sofrimentos e das penúrias a que estão submetidos aqueles que são ainda mais pobres. De todo modo, e isso é o mais relevante nesse momento, nem todo rico vive do luxo e do dispêndio, assim como nem todo pobre é miserável e privado de absolutamente tudo. Mostra da existência das frações de classe é que os ricos podem manifestar insatisfação com seu nível de riqueza, se notarem que acima deles há os que são eventualmente mais ricos, mais dispendiosos e vivem no luxo; do mesmo modo que os pobres podem consentir em "carregar grilhões" (Rousseau, 1983a, p. 278) na medida em que abaixo deles sempre é possível enxergar os que são ainda mais pobres. Não seria exagero afirmar que Rousseau distingue o rico do pobre em termos de propriedade (que traz privilégio) e privação (que traz prejuízo). O rico é o proprietário; os níveis de riqueza é que estabelecerão os ricos e os mais ricos; o pobre é o que vive na privação (nesse aspecto, Neuhouser acerta). Porém os níveis de privação é que estabelecerão os mais pobres e os menos pobres. Portanto, pobreza não significa definitivamente privação absoluta e, nesse aspecto, Neuhouser se equivoca.

Assim, o elemento decisivo a se perceber é que, quando Rousseau lida com a pobreza, ele não se refere exclusivamente àqueles que sofrem com a "privação absoluta". Nem todo pobre convive com a completa falta de acesso ao que é necessário para sobreviver, ao contrário; saber que existem os que estão ainda mais abaixo é uma forma que os pobres encontram para conviver com a própria submissão. Olhar mais abaixo do que acima de si mesmo permite que eles tolerem sua condição e não a abandonem. Certamente aqui reside um dos aspectos políticos mais cruéis e socialmente mais dramáticos produzidos pela desigualdade e pelos níveis

análise "oprime e arruína o operário e o cidadão" (Rousseau, 1983a, p. 294).

11 A diferença entre os ricos pode também ser de natureza moral, tal como enxerga Pignol ao distinguir entre os verdadeiros, porque piedosos, e os falsos ricos. 
profundos de pobreza. No entanto, quando Rousseau se volta explicitamente para a desigualdade, não é absolutamente às diferenças entre os pobres e os mais pobres ou entre os ricos e os mais ricos que ele se refere. 0 que realmente compromete os esforços de construção de uma sociedade legítima e abre as portas para o surgimento do despotismo é a desigualdade que existe entre ricos e pobres, ainda que existam os mais ricos e os menos ricos e os mais pobres e os menos pobres.

\section{Considerações finais}

A desigualdade para Rousseau é um fenômeno que lida sobretudo com a divisão social entre os que têm propriedades e os que são privados delas. Ainda que seja possível encontrar outros elementos que marquem diferenças e assimetrias entre os indivíduos, é especialmente para os problemas nascidos da dominação dos ricos sobre os pobres que o autor concentra suas atenções. Se a desigualdade é o problema central, particularmente no Segundo discurso, é impossível deixar de enxergar que trata-se da desigualdade que vigora entre ricos e pobres. Com isso a pobreza ganha relevância na análise empreendida por Rousseau sem que, no entanto, ele confira a ela o tratamento que sua própria reflexão talvez pudesse exigir.

Assim, diferente do que traz o notável trabalho de Neuhouser, para Rousseau, a pobreza é uma das causas da dominação tanto quanto o é a desigualdade. Do mesmo modo, a pobreza não está circunscrita exclusivamente entre aqueles que sofrem com a privação absoluta dos meios de vida; há frações de classes tanto entre os pobres quanto entre os ricos; no entanto, isso não faz com que o caráter normativo da desigualdade seja orientado em outros termos senão como a distinção entre ricos e pobres.

\section{Referências}

Pignol, C. (2010/2). Pauvreté et fausse richesse chez J.-J. Rousseau: l'économie entre éthique et politique. Cahiers d'économie politique, Paris, 59, p. 45-68.

Fischbach, F. (2017). Como pensar filosoficamente o social? Tradução de Hélio Alexandre da Silva. Cadernos de Filosofia Alemã, São Paulo, 22(4), p. 171-185.

Honneth, A. (2008). La société du mépris : vers une nouvelle Théorie critique. Traduit par Olivier Voirol, Pierre Rusch et Alexandre Dupeyrix. Paris : La Découvert.

Neuhouser, F. (2014). Rousseau's critique of inequality: reconstructing the Second discourse. United Kingdom: Cambridge University Press.

Nicodème, F. (2010). “Corruption”, “mutilation”, "pathologie” : réflexions sur le statut de Rousseau dans la théorie critique (Horkheimer, Adorno, Honneth). Modernités de Rousseau, Paris, 15, p. 131-152.

Rousseau, J-J. (1964). Discours sur l'origine et les fondements de l'inégalité parmi les hommes. In : Ouvres complètes. Paris : Bibliothèque de la Pléiade, Gallimard, 
vol. III.

- (1983a). Discurso sobre a origem e os fundamentos das desigualdades entre os homens. Tradução de Lourdes Santos Machado. São Paulo: Abril. Os pensadores.

(1983b). Do contrato social: ou princípios do direito político. Tradução de Lourdes Santos Machado. São Paulo: Abril. Os pensadores.

- (1995). Emílio ou Da educação. Tradução de Sérgio Milliet. Rio de Janeiro: Editora Bertrand Brasil.

Silva, H. A. (2014). O Iluminismo relutante de Jean-Jacques Rousseau. Philósophos Revista de Filosofia, Goiânia, 19(1), p. 35-62.

Souza, M. G. (2001). Ilustração e história: o pensamento sobre a história no Iluminismo Francês. São Paulo: Discurso Editorial.

Esta obra está licenciada com uma Licença Creative Commons Atribuição-NãoComercial- 